\title{
LONG TERM EVOLUTION OF BALTIC SEA SANDY BEACH FORCED BY WINTER NORTH ATLANTIC OSCILLATION (NAOWI)
}

\author{
Grzegorz Różyński and Piotr Szmytkiewicz ${ }^{1}$
}

\begin{abstract}
The study examines a hypothesis on the coupling between Winter North Atlantic Oscillation (NAOWI) and hydroand morphodynamics of a sandy beach with multiple bars, situated at a Baltic Sea coastal segment in northern Poland. Identification of coincident long-term periodic patterns of shoreline variability and NAOWI is a strong argument for the existence of such a coupling, because the Baltic Sea is purely non-tidal and shoreline evolution is driven entirely by waves. Interestingly, similar periodic patterns were also found in the reconstructed long-term winter wave climate (hourly retrieved significant wave height between $1958-2001$ ). Therefore, the hypothesis received a strong and comprehensive statistical footing. It highlights the fact that long-term periodic changes in winter energy fluxes from air through waves to the beach remain imprinted in shoreline evolution. Hence, any climate change driven modifications of global meteorological patterns, such as NAOWI, may have vital implications for Baltic Sea beaches in coming decades.
\end{abstract}

Keywords: Baltic Sea, shoreline change, coastal hydro- and morphodynamics

\section{INTRODUCTION}

The Baltic Sea, connected with worldwide Ocean only through the Danish Straits, is a non-tidal and shallow water body, see Fig. 1 (left). It encompasses the area $S=415,000 \mathrm{~km} 2$ and has the volume $\mathrm{V}=21,700 \mathrm{~km} 3$, including Kattegat, BACC, 2008. Despite restricted water exchange through the narrow entrance area it is very dynamic being strongly influenced by large-scale atmospheric circulations, as demonstrated by Różyński \& Pruszak, 2010. Searching for the explanation of long-term periodic components in shoreline evolution of a coastal segment in Poland, they found that the reconstructed wave climate for January (significant wave height $H_{s}$ between 1958 - 2001) contained two very strong components with the same periods. Also, one such component was identified for February. Further attempts to correlate these periodic components with individual monthly indices of North Atlantic Oscillation (NAO) gave only partly-satisfactory results, because only the component with the longest period of several decades could be regarded as a driver of variations of hydrodynamic regimes with a similar period.
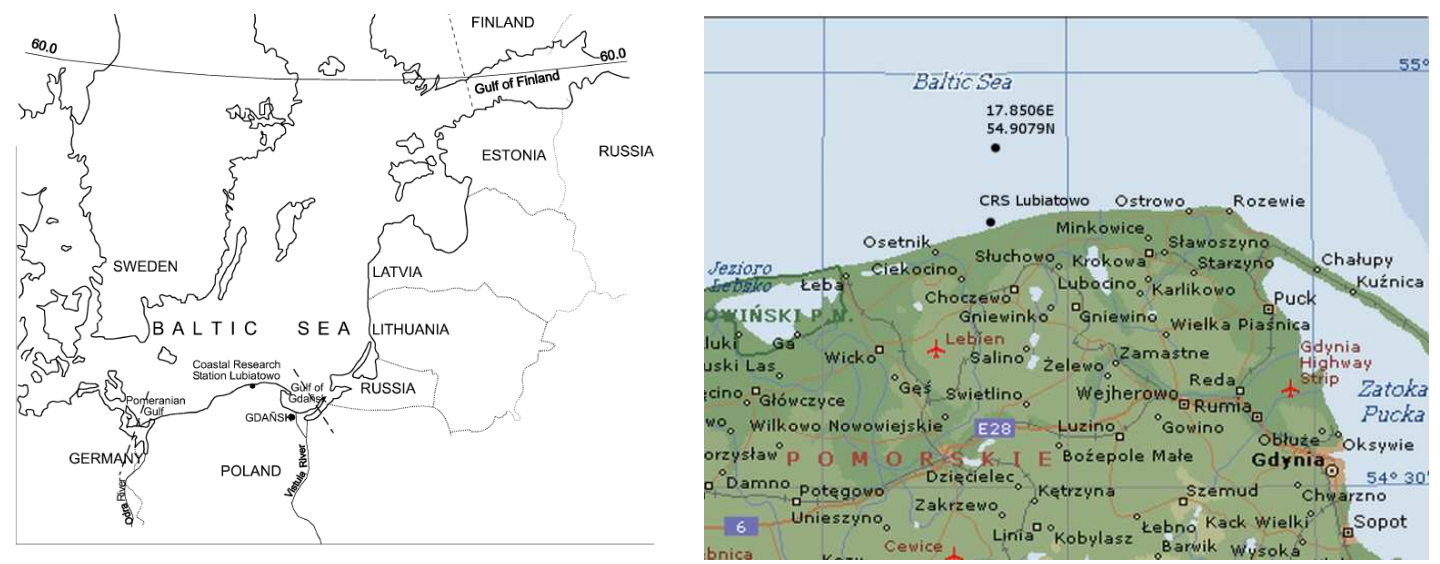

Figure 1. Baltic Sea (left) and study area - CRS Lubiatowo with wave climate reconstruction coordinates (right).

Since the so far studies were only half-conclusive it was decided to search for more vivid couplings between the atmospheric forcing, represented by NAO-type patterns, and hydrodynamic regimes that force long-term periodic variations of shoreline configuration. Therefore, the behavior of winter index of North Atlantic Oscillation (NAOWI) was closely inspected, as NAOWI features the atmospheric conditions throughout the whole winter season from December through March. Hence, it

\footnotetext{
${ }^{1}$ Inst. Hydroengineering, Polish Acad. Sci. (IBW PAN), 7 Kościerska, 80-328 Gdańsk, Poland
} 
should be a better proxy indicator of hydro- and morphodynamic patterns than individual monthly NAO indices.

\section{STUDY AREA}

The Coastal Research Station (CRS) of IBW PAN is an establishment, where geodetically referenced long-term beach topography data, including shoreline configurations, have been collected since 1983. Since 1987 geodetically referenced records of nearshore bathymetry have also been acquired. The Station is located at Lubiatowo, Poland, on the southern coast of the Baltic Sea, Fig. 1 (left) and Fig. 2. The beach is a highly dissipative system with multiple longshore bars; the number of crests varies between $3-6$ with 4 on average, $c f$. Fig. 4 . The mean slope is mild and usually equals $m=$ $\tan \alpha=1-1.5 \%$ with a median grain size of $D_{50}=0.22 \mathrm{~mm}$. Although the measurements indicate longterm beach equilibrium, the shoreline is not perfectly stable. The surveys are attached to a local geodetic system, see Fig. 3 (left), so all measurements taken at different times and along different lines are fully consistent. In total, the surveyed area covers $2,600 \mathrm{~m}$ of alongshore distance with 27 crossshore profiles uniformly spaced at $100 \mathrm{~m}$. Their enumeration is explained in Fig. 3; 8 profiles in the eastern sector were fixed first, the remaining ones with higher numbers were added later. The shoreline position data represent 16 years of measurements, see Fig. 3 (right). The surveys started in Sep. 1983 and typically have been repeated every four weeks (28 days); the last survey included in this study was carried out in Sep. 1999. This data set was thoroughly analyzed with multi-channel singular spectrum analysis (MSSA), see Różyński, 2005, who detected long-term shoreline standing waves, one with $T=$ several decades and the other with $T=8$ years, Fig. 5. Their presence inspired the search for hydrodynamic patterns with similar periodic components, as in the absence of tides wave-driven hydrodynamics is the only agent driving shoreline/seabed variability.

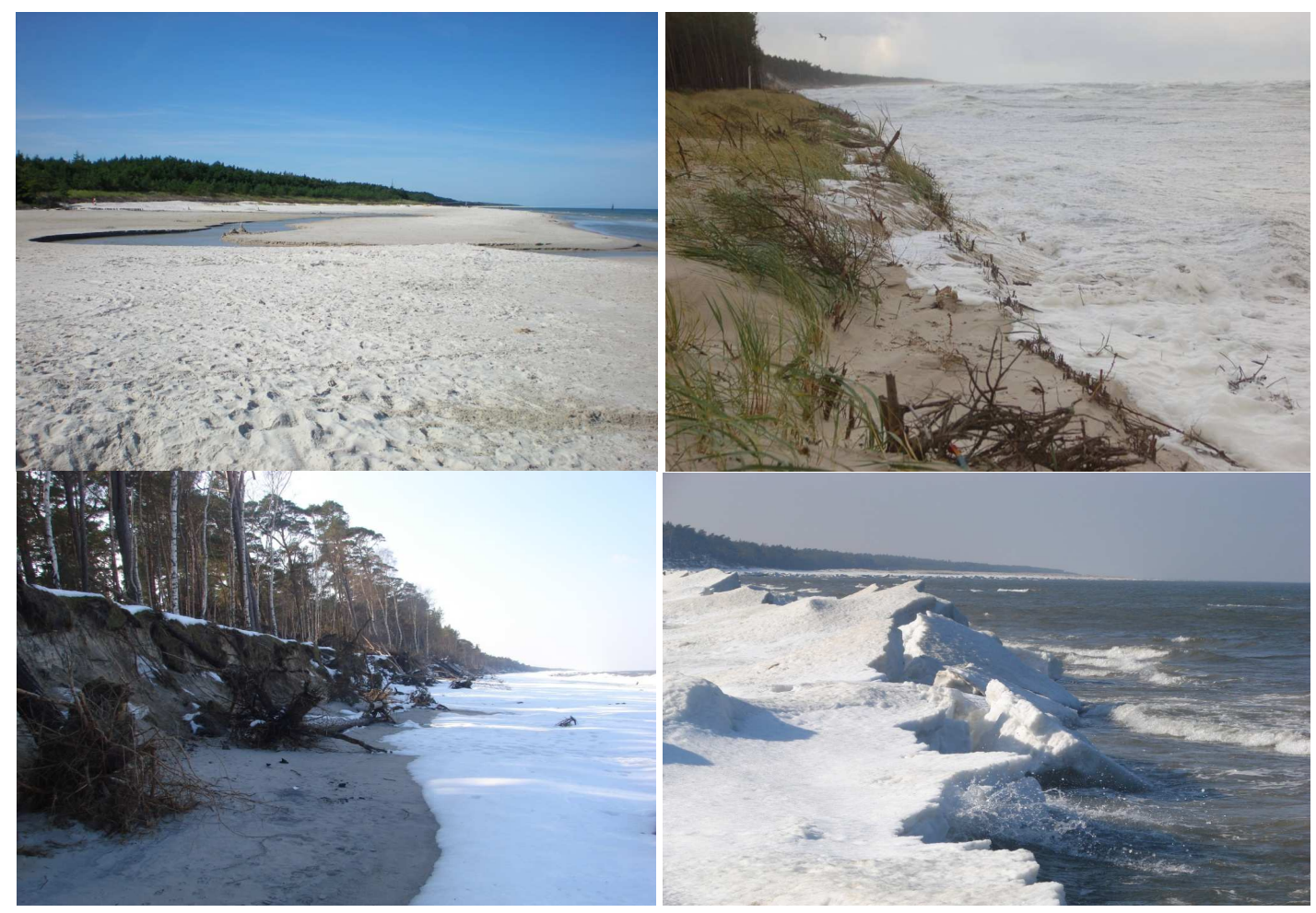

Figure 2. Coast at Lubiatowo, PL: wide beach in calm period (top left), direct wave attack on dune during storm (top right), heavily damaged dunes in winter (bottom left) and ice beach protection later in winter (bottom right). 

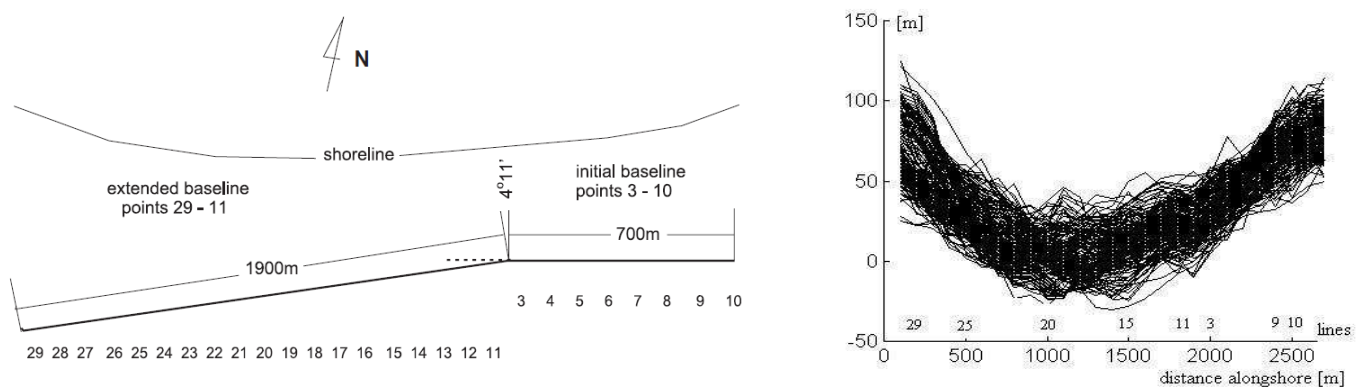

Figure 3. Geodetic base at CRS Lubiatowo (left) and shoreline configurations 1983 - 1999 (right).
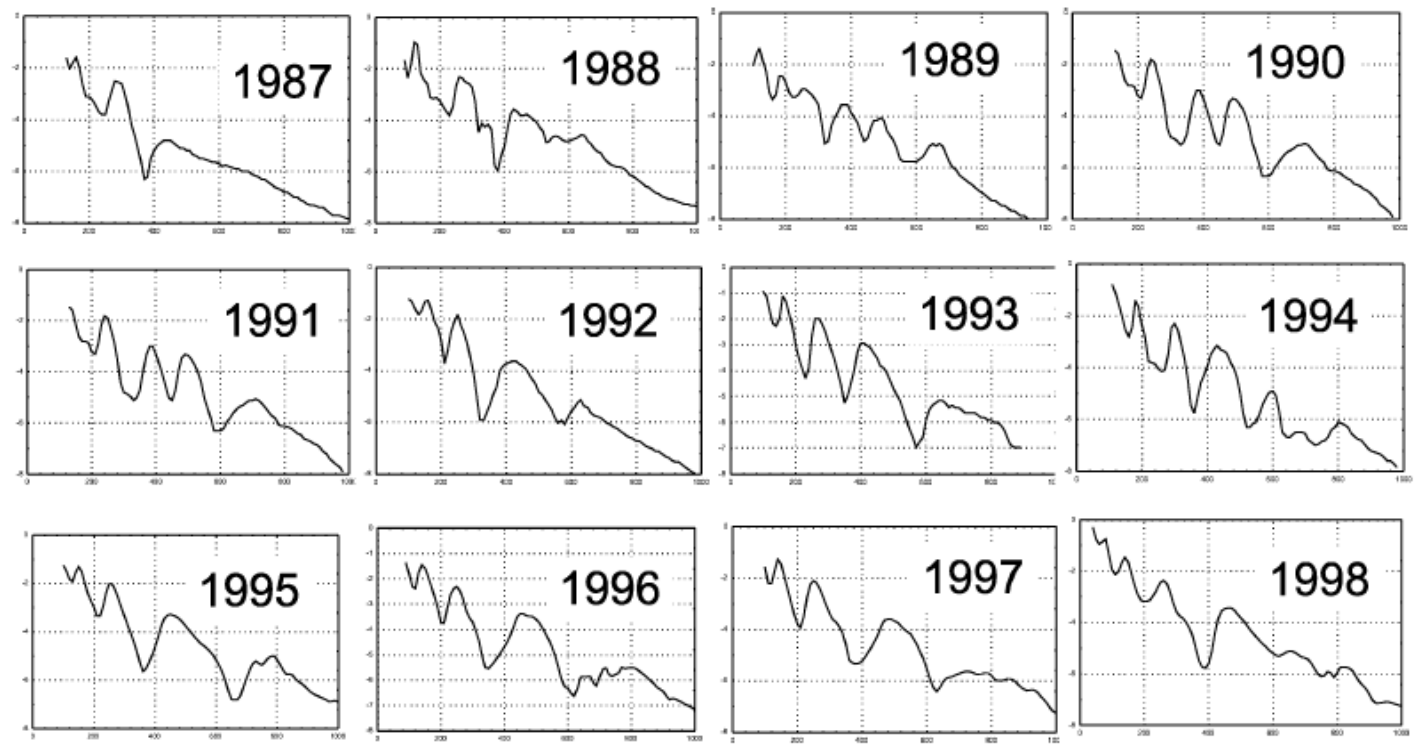

Figure 4. Variability of exemplary cross-shore profile: 3 - 6 crests visible, usually 4.
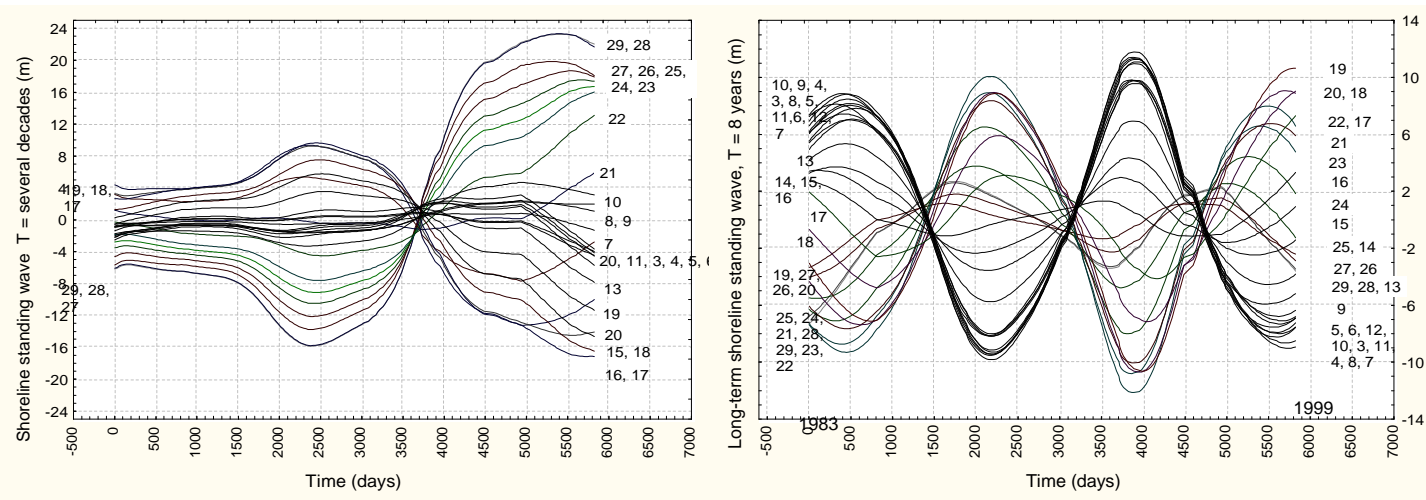

Figure 5. Shoreline periodic components in form of standing waves: $T=$ several decades (left) and $T=8$ years (right) - numbers denote profile lines of geodetic base.

\section{ANALYSIS \& RESULTS}

Hydrodynamic data in which significant periodic components coincide with those from shoreline evolution analysis were obtained during a hindcast procedure, shown in Fig. 6. 


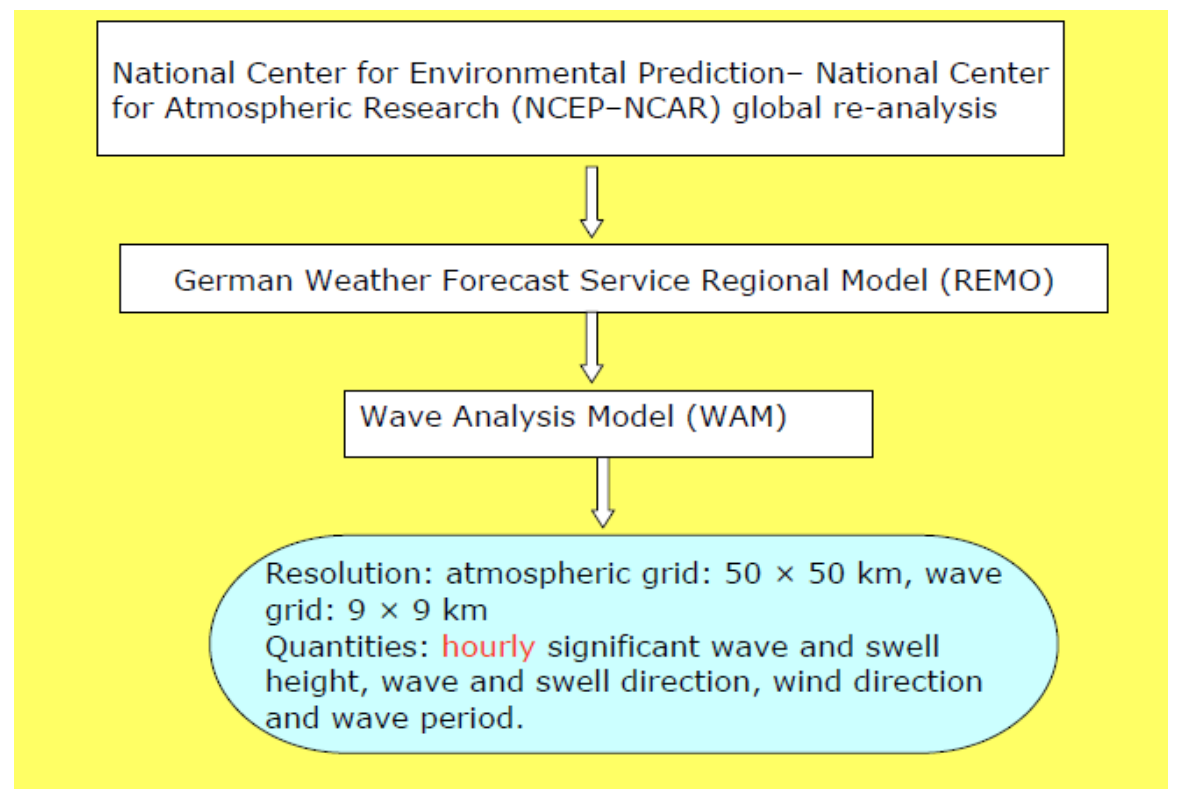

Figure 6. Wave climate hindcast procedure, Różyński \& Pruszak, 2010

The hindcast covers the period from 1958 until 2001 and provides information on hourly hindcast wind and wave climate. The former was obtained for $50 \times 50 \mathrm{~km}$ cells, the latter had a finer $9 \times 9 \mathrm{~km}$ grid cells. The wind information contains data on wind speed and direction, the wave data include sea and swell parameters (significant wave height $H_{s}$, wave period and direction). The coordinates of hindcast location near CRS Lubiatowo are shown in Fig. 1 (right); more detailed description of the hindcast procedure can be found in Różyński and Pruszak, 2010.

Fig. 7 presents the time series of mean monthly annual $H_{s}$ and the associated raw spectral densities (periodograms). It can be seen that both periodic components are visible only in Jan. and one of them in Feb. Also, the periodograms in those months have the strongest power when compared to Dec. and Mar. It can therefore be inferred that the most persistent spectral component features a very long-term behavior. Indeed, the same spectral components were found in the associated time series of NAO for Jan. and Feb. for the 1950 - 2006 period, as illustrated through their periodograms in Fig. 8. However, those series did not contain any significant components with the period of 8 years. Thus, it was decided to investigate the NAOWI series in search of the 8-year component. This series, spanning the very long period 1865 - 2010, is shown in Fig. 8 together with its periodogram.

The NAOWI index represents normalized, average winter pressure difference (December through March) between Iceland and one of the southern locations, typically Gibraltar. We can see that throughout 150 years of observations the two key periodic component are significant (great spectral power) and persistent. Since the same periodic components are imprinted in shoreline evolution it can be therefore concluded that winter atmospheric conditions over the North Atlantic have a profound impact on coastal processes in the Baltic Sea. From the inspection of ordinary NAO indices for individual (winter) months, $c f$. Fig. 7, we already know that the strongest periodic component is evident in Jan. and Feb. The inclusion of NAOWI series revealed that also the $2^{\text {nd }}$ component, containing 8 year periodicity, is very strong. The fact that it failed to be detected in the series of individual monthly NAO indices has the following consequences: (i) the 8-year oscillation can appear in any on the winter month from Dec. through Mar. and the times (months) of consecutive appearances are random and independent, (ii) the duration of individual spells is rather short, (iii) appearances may occur in periods overlapping the end of one month and beginning of the next. The resultant spectral power is thus too small to be seen in the periodograms of monthly NAO series. However, taken the whole winter season together it is very significant, as it was found to be imprinted in shoreline evolution at CRS Lubiatowo. 

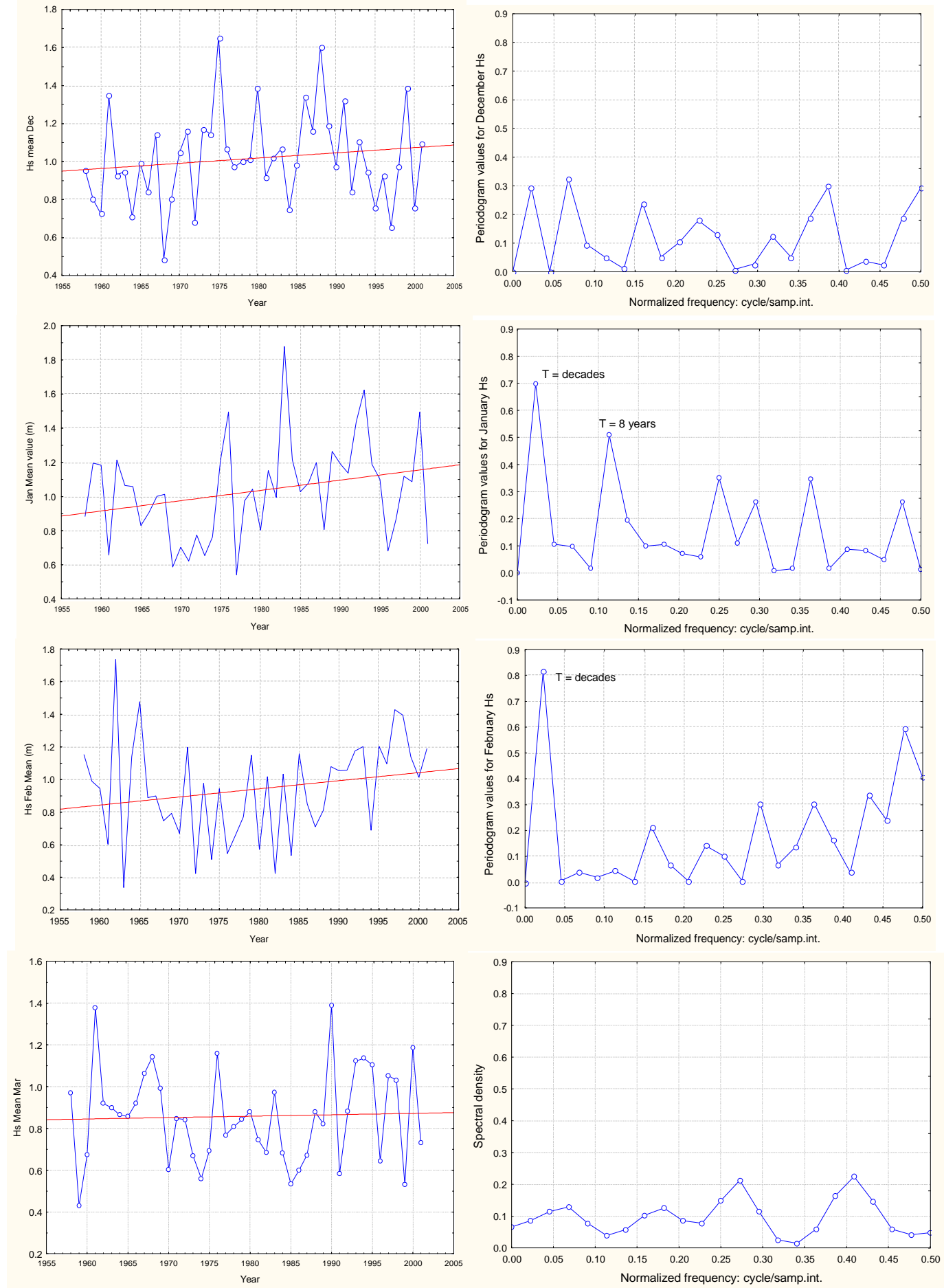

Figure 7. Mean annual $H_{s}$ and periodogram in 1958 - 2001 for Dec., Jan., Feb. and Mar, Różyński \& Pruszak, 2010. 

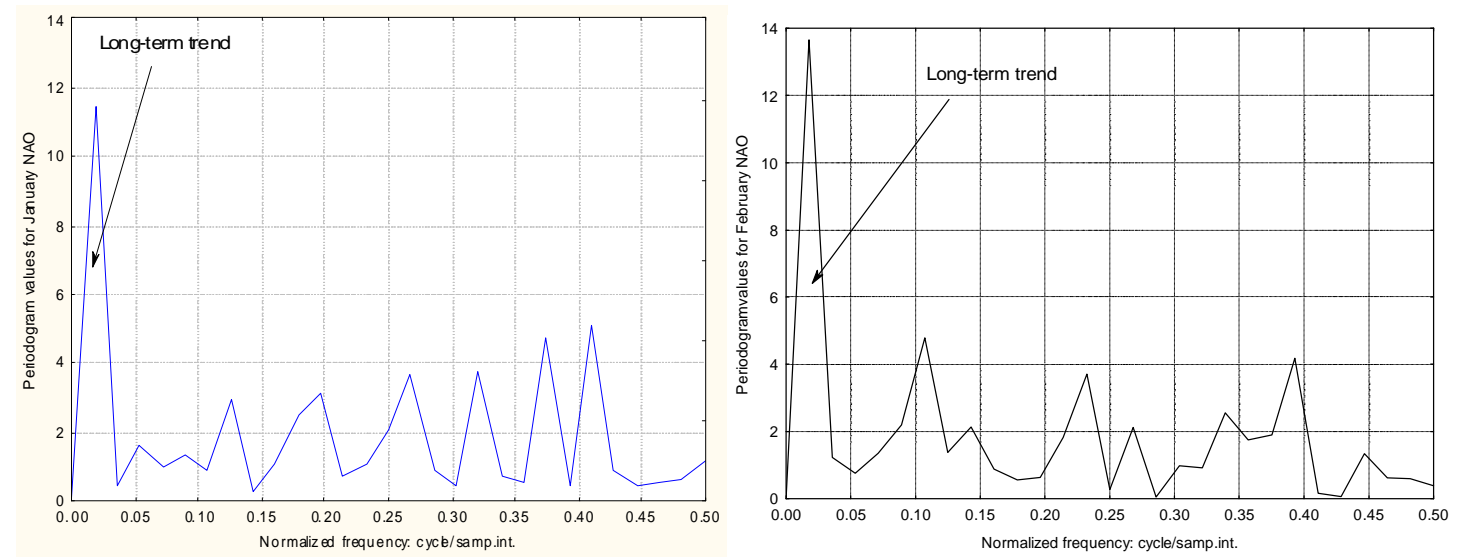

Figure 7. Periodograms of NAO for Jan. (left) and Feb. (right); long-term trend is clearly dominant
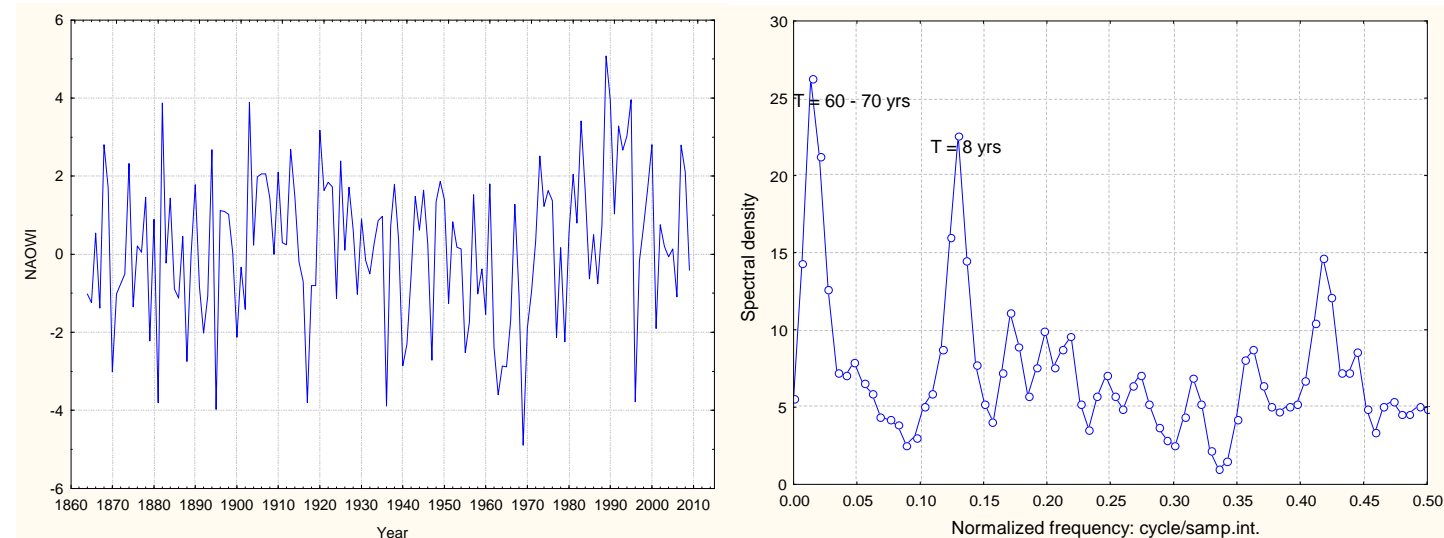

Figure 8. NAOWI series and its periodogram; both periodic components clearly visible
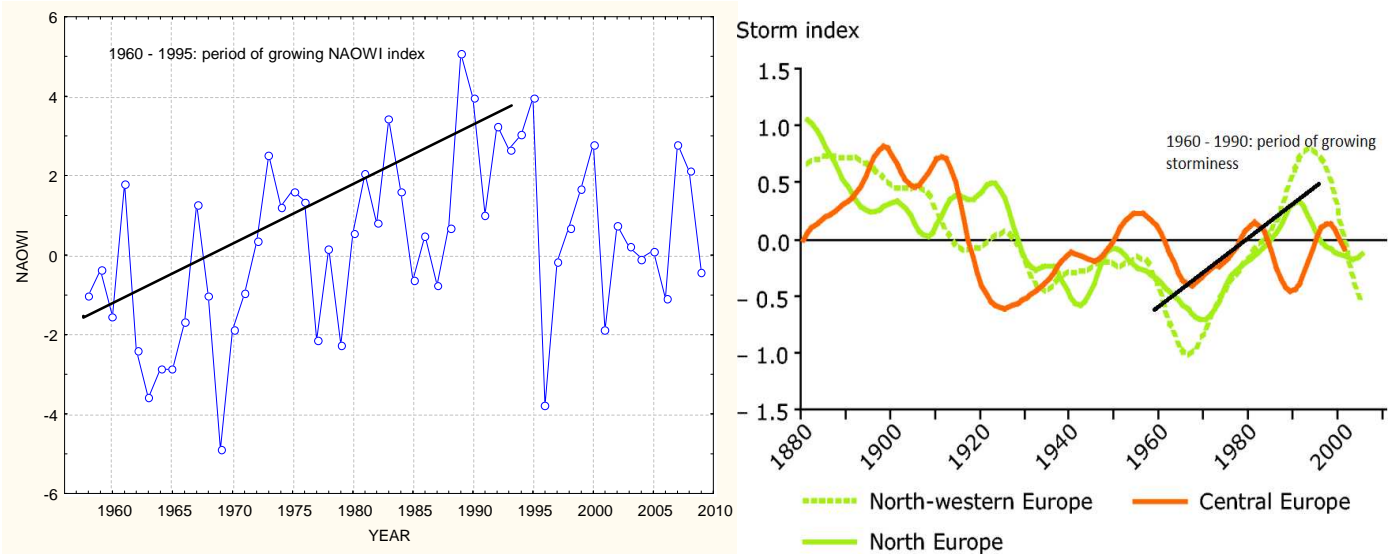

Figure 9. Qualitative resemblance - concurrent trends of NAOWI (left) and time series of storm indices (right)

High dependence of Baltic Sea hydrodynamic regimes and shoreline evolution on atmospheric patterns in winter becomes clear when the NAOWI series is compared with time series of normalized storm indices, obtained from daily atmospheric pressure differences $\Delta \mathrm{p} / 24 \mathrm{~h}$. This comparison is presented in Fig. 9. Strong qualitative resemblance of NAOWI and storm indices for north (Baltic Sea area) and north-western Europe is evident since 1960; first there is a strong growing trend between 1960 - 1990, which is followed by a certain decline afterwards. Therefore, the NAOWI can be treated as a proxy indicator of storminess, so for higher, positive values of the NAOWI one can expect stormier winds and warmer temperature. The latter means that protective role of ice cover, $c f$. Fig. 2 (bottom 
right), will be diminished in such instances, producing favorable environment for accelerated coastal erosion of sandy Baltic beaches.

Fig. 10 illustrates the long term trend of NAOWI since 1950, where the rapid growth in $1960-$ 1990 and some decline after 1995 are vividly seen. It is associated with the greatest peak of the periodogram shown in Fig. 8 (right) and represents the periodic behavior of about 70 years. The implications of this trend related to hydrodynamic regimes are shown in Fig. 11, where the hindcast (hourly estimated) occurrences for $H_{s}>1 \mathrm{~m}$ are plotted for each calendar month for two sub-periods: 1958-1979 and 1980-2001, cf. Różyński \& Pruszak, 2010. A very prominent growth of stormy conditions can be seen in Jan., also in Feb. Oct. and Nov. some growth of stormier weather could be observed. On the right hand side the associated change of wave direction is presented; as could be expected the greater values of long-term trend (and NAOWI index in general) in $1980-2001$ produced more waves propagating east from the western sector at the expense of waves propagating south, south west and west from northern, north-eastern and the eastern sector. The increase of westerly winds in winter means that it is usually accompanied by warmer winter temperatures above freezing. Thus, more storms coincide with the reduced formation of coastal ice, so the dunes must absorb substantially greater energy fluxes in winter; the effect of wave action on dunes after winter storms can be seen in Fig. 2 (bottom right).

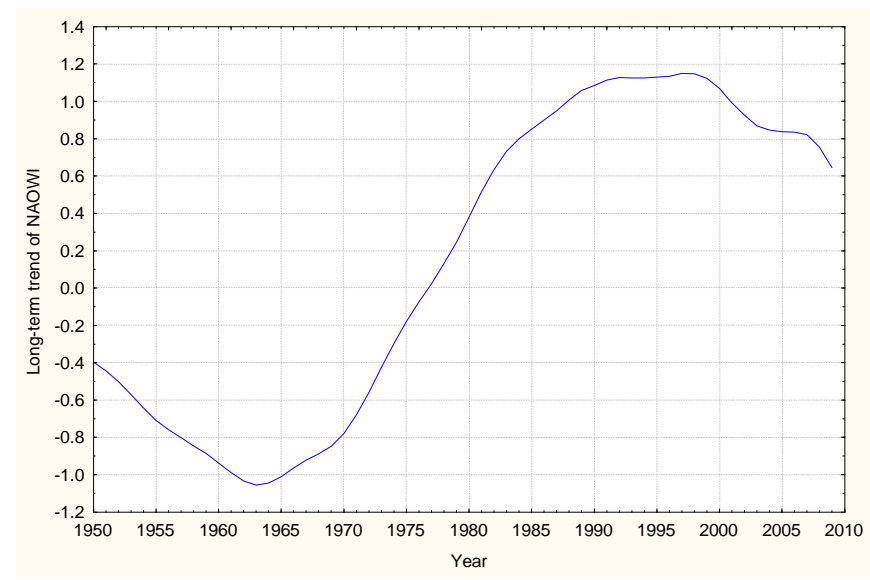

Figure 10. Long term trend of NAOWI since 1950
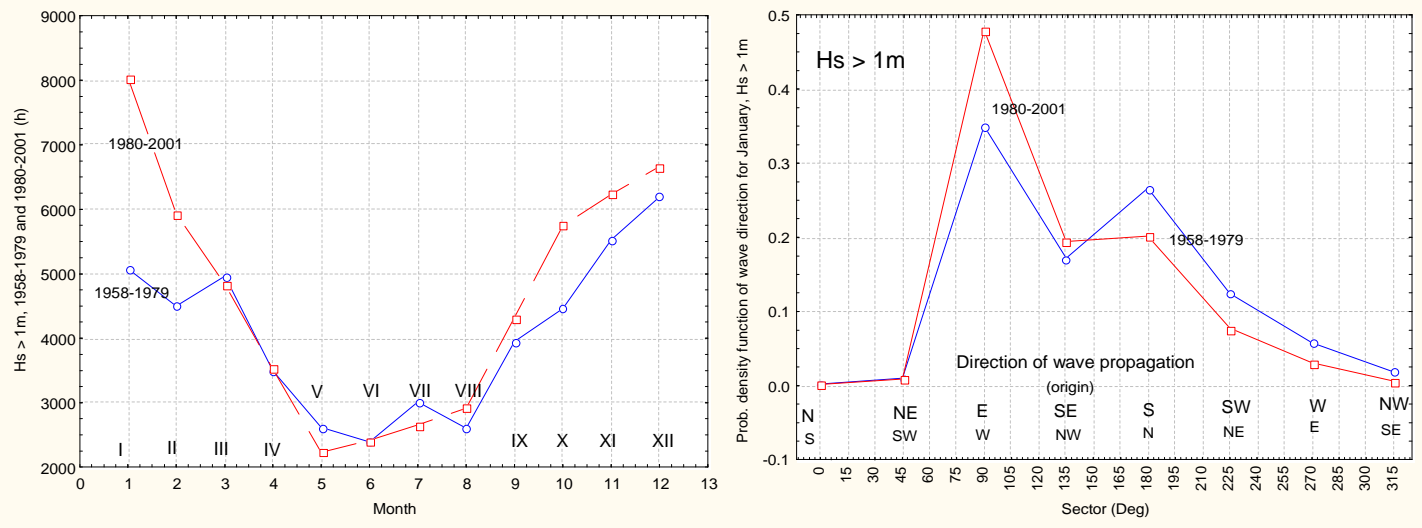

Figure 11. Growth of storminess due to positive NAOWI trend - number of hours with $H_{s}>1 \mathrm{~m}$ in each calendar month (left) and the associated change in wave direction (right). 


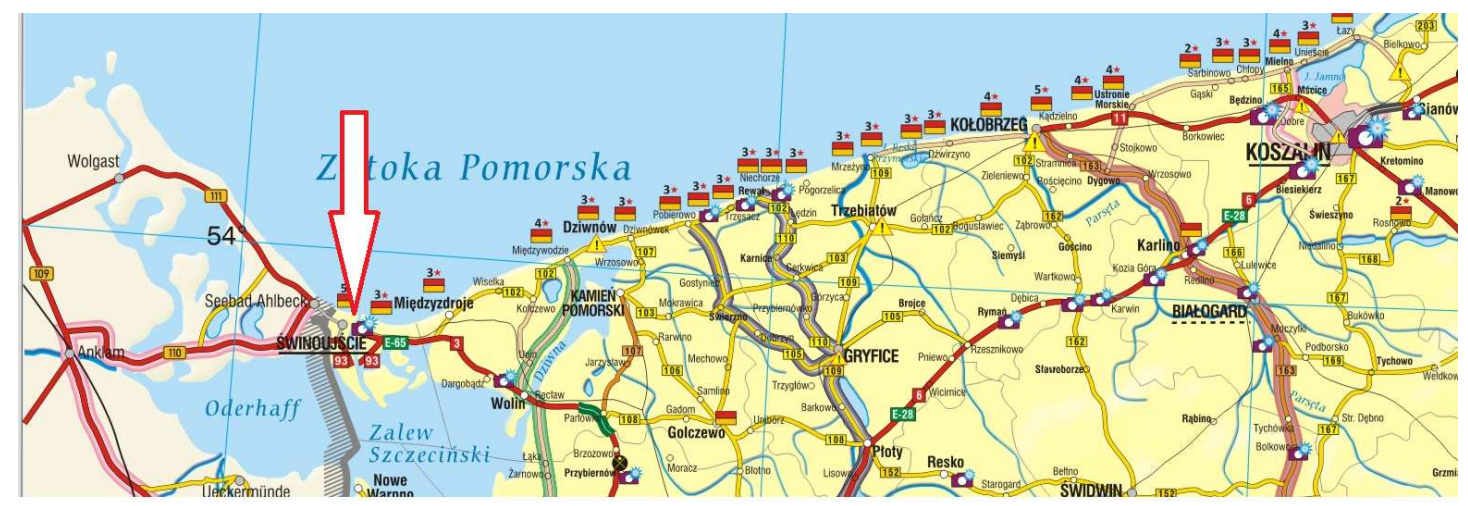

\section{Figure 12. Location of Świnoujście city and harbor}

Further research on the NAOWI impacts was focused on the longest water level datasets in Poland, derived from the gauge situated at a navigational channel to a harbor at Świnoujście - the city on the border with Germany - see the arrow in Fig. 12. The water level time series is presented in Fig. 13; it represents mean values of water level for Dec. through Mar. periods (DJFM) from 1811 until 2000; the gap 1945 - 1951 results from WW II suspension of measurements. Decomposition of this series with the SSA method, $c f$. Vautard et. al., 1992 identified nontrivial components whose spectral behavior was found to be identical to the key NAOWI elements, i.e. the long-term trend and the 8 year cycle. The normalized NAOWI and DJFM components are jointly plotted in Fig. 14.

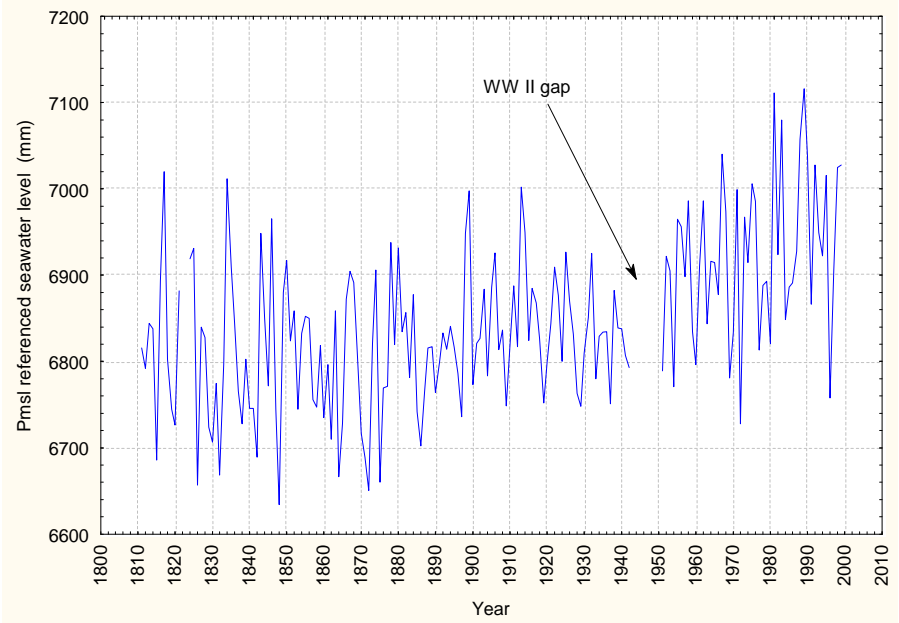

Figure. 13 Mean DJFM water levels at Świnoujście 1811 - 2000

Their comparison yields further insight. It can be seen that both long-term trends grew concurrently between 1890 - 1910, when they both peaked and then declined consistently until 1930. These periods can be explained by the coupling of both trends. However, after 1930 they decoupled completely and permanent growth of mean DJFM sea level has been persisting irrespective of fluctuations of the NAOWI trend. The most plausible explanation is related to the beginning of recent climate change induced sea level rise, which has become a dominant feature of seawater level records after 1930 .

The comparison of 8 year cycles shows consistent, in-phase variations before 1914 and after 1960 for the instances of high amplitude variations. This evidences the NAOWI - seawater level coupling and demonstrates its persistence and strength. Discrepancies between 1915-1960 are probably related to the presence of WWII gap of seawater level measurements; their SSA decomposition was performed on primitively concatenated data that could bring about inconsistencies of components whose time scale (8 years) is similar to the gap (1945 - 1951). Also, smaller amplitudes of the 8 year cycle between 1920 1950 could contribute to temporary decoupling of the atmospheric component (forcing) and seawater variations. 

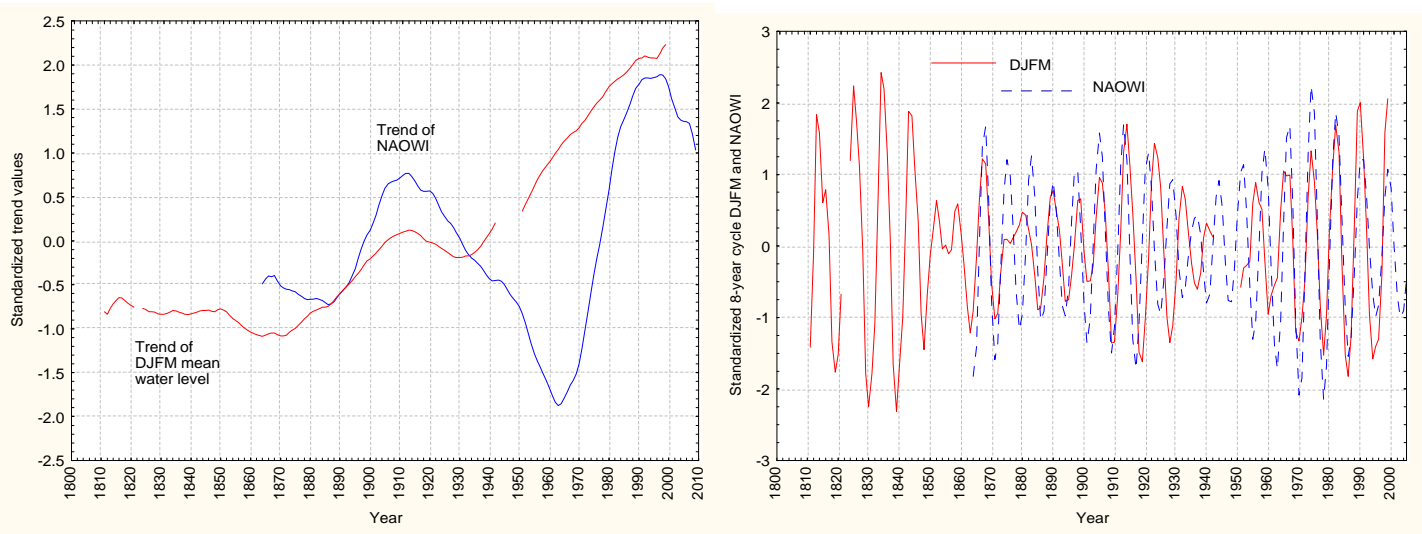

Figure 14. Couplings of long-term trend (left) and 8-year cycle (right) of NAOWI and seawater level components at Świnoujście

\section{CONCLUSIONS}

1. The study found more in-depth insight into the couplings between large atmospheric circulation from the North Atlantic and hydro- and morphodynamic response of the Baltic Sea coast in Poland.

2. Winter wave climate is the most energetic, so its aftermath is imprinted in shoreline variations in the form of shoreline standing waves.

3. Morphodynamic response consists in periodic shoreline oscillations in the form of standing waves, one featuring very long-term period of several decades and the other with $\mathrm{T}=8$ years.

4. January hydrodynamic regimes of deepwater significant wave height contain two significant periodic components with the periods corresponding to morphodynamic shoreline variations.

5. February hydrodynamic regimes of $H_{s}$ contain one long term significant periodic component, corresponding to long-term morphodynamic shoreline variations of several decades. The component with $\mathrm{T}=8$ years is missing.

6. Winter index of North Atlantic Oscillation (NAOWI), featuring average atmospheric pressure difference in Dec. - Mar. periods, contain both significant periodic components, whose periods are consistent with hydro- and morphodynamic variations.

7. The longest NAOWI component is the most persistent, as it could be identified in the time series of NAO calculated independently for Jan. and Feb.; it was not identified in Dec. and Mar. It can therefore be inferred it develops in later Dec., persists in Jan. and Feb. and then disintegrates in early Mar.

8. The 8-year component cannot be discerned in separate Jan. and Feb. NAO time series, but is vividly significant in the NAOWI series. It is also significant in hydrodynamic regimes of Jan. Hence, it can be inferred that: (i) the spells of 8-year oscillation are rather short; they can appear independently and partly cover two neighboring months, (ii) it can develop in Dec., persist in Jan and decay in Feb., (iii) it can develop in Dec. and decay in Jan., (iv) it can develop in Jan. and decay in Feb.

9. NAOWI is a very good proxy indicator of storminess; its positive values denote more storms and warmer temperature; thus the formation of coastal ice barrier is retarded and winter erosion enhanced.

10. Both significant NAOWI periodic components were also found in the longest sea water level data from Świnoujście. The analysis of very long term behavior found that by 1930 the NAOWI and sea water level varied consistently, reflecting greater and more frequent storm surges during the positive NAOWI phase. After that time the water level and NAOWI decoupled and the former started to grow rapidly, so 1930 can be viewed as the beginning of climate change induce sea level rise in the Baltic Sea.

11. The peaks of 8-year oscillation of water level and NAOWI coincide perfectly when their amplitudes are high, i.e. before 1914 and after 1960. The data gap in the water level series (1945 - 
1951) and primitive concatenation of both sends of that series, when key periodic components were extracted can also be a reason why this consistency was lost between $1915-1960$.

12. Further research should concentrate on the spatial extent of NAOWI impacts over the Baltic Sea. For this end water level data from western (Kattegat, Danish Straits), northern (Bothnian Bay) and eastern (Gulf of Finland) parts of the Baltic Sea should be examined to seek the same periodic components as were found in the hydrodynamic of $H_{s}$ and water levels in Poland.

\section{ACKNOWLEDGMENTS}

The support of the European Commission through FP7-SPACE-2009-1, Contract 242284 - FIELD_AC ("Fluxes, Interactions and Environment at the Land-Ocean Boundary. Downscaling, Assimilation and Coupling."), is gratefully acknowledged.

\section{REFERENCES}

Różyński, G., 2005. Long term shoreline response of a non-tidal, barred coast, Coastal Engineering, 52 (2005), pp 79-91

Różyński, G., Pruszak, Z., 2010. Long-Term Rise of Storminess of the Baltic Sea near Poland; Possible Origin and Consequences, Proceedings of $32^{\text {nd }}$ ICCE Conference, Shanghai 2010, China, https://journals.tdl.org/ICCE/article/view/974/pdf_61.

The BACC Author Team, 2008. Assessment of Climate Change for the Baltic Sea Basin. SpringerVerlag Berlin Heidelberg, ISBN: 978-3-540-72785-9, 473pp.

Vautard, R., Yiou, P., Ghil, M., 1992. Singular spectrum analysis: A toolkit for short, noisy, chaotic signals. Physica D, 158: 95-126. 